Annales Geophysicae (2002) 20: 225-235 (C) European Geophysical Society 2002

\title{
A study into the effect of the diurnal tide on the structure of the background mesosphere and thermosphere using the new coupled middle atmosphere and thermosphere (CMAT) general circulation model
}

\author{
M. J. Harris ${ }^{1}$, N. F. Arnold ${ }^{2}$, and A. D. Aylward ${ }^{1}$ \\ ${ }^{1}$ Atmospheric Physics Laboratory, University College London, 67-73, Riding House Street, London W1P 7PP, UK \\ ${ }^{2}$ Department of Physics and Astronomy, University of Leicester, University Road, Leicester, LE1 7RH, UK
}

Received: 30 November 2000 - Revised: 8 July 2007 - Accepted: 17 July 2007

\begin{abstract}
A new coupled middle atmosphere and thermosphere general circulation model has been developed, and some first results are presented. An investigation into the effects of the diurnal tide upon the mean composition, dynamics and energetics was carried out for equinox conditions. Previous studies have shown that tides deplete mean atomic oxygen in the upper mesosphere-lower thermosphere due to an increased recombination in the tidal displaced air parcels. The model runs presented suggest that the mean residual circulation associated with the tidal dissipation also plays an important role. Stronger lower boundary tidal forcing was seen to increase the equatorial local diurnal maximum of atomic oxygen and the associated $0\left({ }^{1} \mathrm{~S}\right) 557.7 \mathrm{~nm}$ green line volume emission rates. The changes in the mean background temperature structure were found to correspond to changes in the mean circulation and exothermic chemical heating.

Key words. Atmospheric composition and structure (middle atmosphere - composition and chemistry) Meterology and atmospheric dynamics (middle atmosphere dynamics; waves and tides)
\end{abstract}

\section{Introduction}

There have been numerous modelling studies of tides in the Mesosphere Lower Thermosphere (MLT) region, many of which involve the comparison with observations made by instruments on board the Upper Atmosphere Research Satellite (UARS) (e.g. Roble and Ridley, 1994; Burrage et al., 1995; Akmaev et al., 1996; Hagan et al., 1997; McLandres et al., 1997; Wu et al., 1997; Yee et al., 1997; Roble and Shepherd, 1997; Yudin et al., 1998). These have been especially useful in placing constraints on processes that influence the magnitude of the diurnal tide in the MLT region. However, there is still uncertainty with respect to much of the physics that governs the background atmospheric structure of this region,

Correspondence to: M. J. Harris

(matthew@apg.ph.ucl.ac.uk) such as collisionally induced $\mathrm{CO}_{2} 15 \mu \mathrm{m}$ radiative cooling, exothermic chemical heating, and gravity wave dissipative heating, turbulence, and momentum drag. The situation is made more complicated by the nonlinear coupling of energetics, dynamics, and photochemistry.

Roble and Shepherd (1997) used the National Center for Atmospheric Research Thermosphere-IonosphereMesosphere-Electrodynamics General Circulation Model (NCAR TIME-GCM, Roble and Ridley, 1994) to investigate the effects of increased lower boundary tidal forcing on parameters such as meridional wind, atomic oxygen distribution, and $0\left({ }^{1} \mathrm{~S}\right) 557.7 \mathrm{~nm}$ green line volume emission rates in the MLT region. They showed that tides play an important role in atomic oxygen distribution, leading to depletions in mean atomic oxygen density at the equator, in agreement with Forbes et al. (1993) and the later study of Angelats i Col and Forbes (1998). The first mechanism put forward for this depletion was proposed by Akmaev and Shved (1980), who suggested that the net recombination increased in tidal displaced parcels of air. Angelats i Col and Forbes (1998) found that the mean vertical transport contributed to the depletion of $\mathrm{O}$ at the equator. They showed that a net downward vertical motion between $85-100 \mathrm{~km}$ at the equator would deplete $\mathrm{O}$ through the transport to a region of increased recombination. It is, however, worth noting that the vertical wind fields derived in their paper showed a region of net downwelling at the equator, and upwelling in the tropics. This differs from the derived fields for January and October presented by Miyahara et al. (1991) and Fauliot et al. (1997), who showed cells of net upwelling at the equator, and downwelling in the tropics in the $80-105 \mathrm{~km}$ region.

In this paper, an investigation is made into the relative magnitude of the processes that are responsible for the production and loss of atomic oxygen in the mean field, and the effect of tides upon the mean temperature structure due to variations in exothermic chemical heating and mean circulation. This is carried out using the newly developed University College London Coupled Middle Atmosphere and Thermosphere (CMAT) general circulation model. 
M. J. Harris et al.: A study into the effect of the diurnal tide
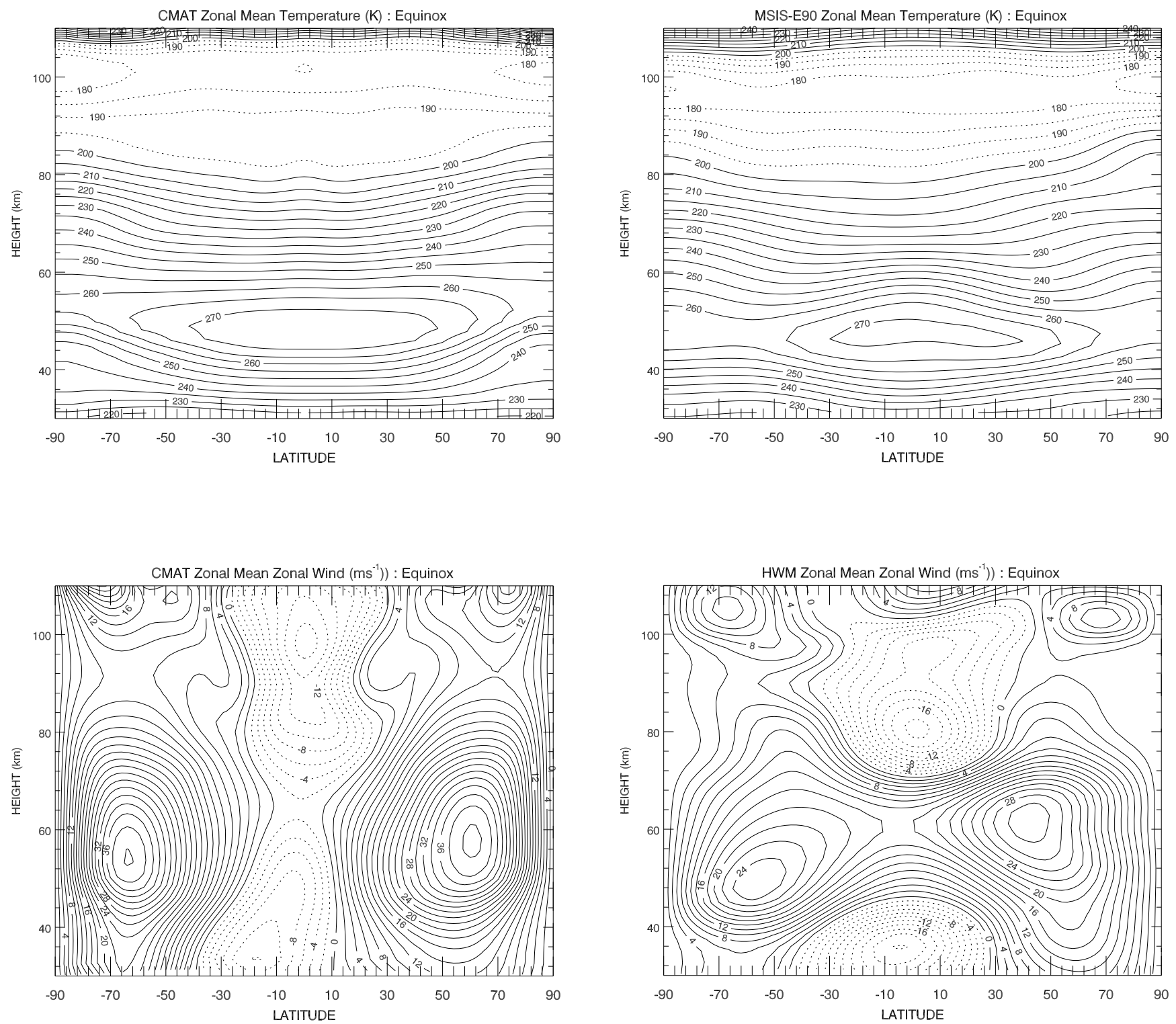

Fig. 1. Zonal mean temperature $(K)$ (top) and zonal mean zonal wind $\left(\mathrm{ms}^{-1}\right)$ (bottom) as calculated by CMAT for equinox. Positive values denote eastward winds.

\section{The Coupled Middle Atmosphere and Thermosphere (CMAT) GCM}

CMAT is an extension of the University College London time dependent 3-dimensional Coupled Thermosphere Ionosphere Plasmasphere (CTIP) model (see Fuller-Rowell et al., 1996; Millward et al.,1996). It covers a vertical range from $10 \mathrm{mbar}(\sim 30 \mathrm{~km})$ to 7.587 pbar $(\sim 300-600 \mathrm{~km})$, numerically solving the primitive nonlinear coupled equations of energy, momentum, and continuity with a forward time centred space finite difference scheme. The following points highlight the main features of the model, which include updates to the original thermospheric scheme, and extensions required in order to simulate mesospheric energetics, dynamics and composition. A detailed description of CMAT is given by

Fig. 2. Zonal mean temperature $(K)$ as given by MSIS-E90 (top), and zonal mean zonal wind as given by $\operatorname{HWM}\left(\mathrm{ms}^{-1}\right)$ (bottom) for equinox. Positive values denote eastward winds.

Harris (2000).

(I) The model grid has a third scale height vertical, $2^{\circ}$ latitude and an $18^{\circ}$ longitudinal resolution.

(II) Thermospheric heating, photodissociation and photoionisation are calculated due to the absorption of solar X-ray, EUV and UV radiation between 0.1$194 \mathrm{~nm}$. The fluxes, absorption and ionisation cross sections between $0.1-105 \mathrm{~nm}$ are summarized by FullerRowell (1992), and those between 105-194 nm in the Schumann-Runge continuum are given by Torr et al. (1980a), and Torr et al. (1980b). The EUV heating efficiencies are due to Roble (1987). 
(III) Mesospheric heating is calculated due to the absorption of solar radiation by the ozone in the Chappuis, Huggins and Hartley bands, by $\mathrm{O}_{2}$ in the Schumann-Runge Bands (Strobel, 1978), and exothermic neutral chemistry. Middle atmosphere heating efficiencies are due to Mlynczak and Solomon (1993).

(IV) The following radiative cooling parameterisations are included: $9.6 \mu \mathrm{m} \mathrm{NO}$ emission (Kockarts (1980)), $63 \mu \mathrm{m}$ fine structure atomic oxygen emission (Bates (1951), Fuller-Rowell private communication (1998)), LTE and non-LTE $15.6 \mu \mathrm{m} \mathrm{CO} \mathrm{CO}_{2}$ emission, with an atomic oxygen collisional deactivation rate coefficient of $3.5 \times 10^{-12} \mathrm{~s}^{-1}$; and $\mathrm{O}_{3} 9.6 \mu \mathrm{m}$ radiative emission (see Fomichev and Blanchet (1995)).

(V) A full mesosphere-thermosphere neutral chemical scheme is included (Allen et al., 1984; Solomon et al., 1985; Fuller-Rowell, 1992), incorporating JPL-97 reaction rate coefficients (DeMore et al., 1997). The effect of transport on major constituent continuity with mutual molecular diffusion is solved for $\mathrm{O}_{2}, \mathrm{~N}_{2}$, and $\mathrm{O}_{\mathrm{x}}=(\mathrm{O}$ $+\mathrm{O}_{3}$ ) (see Fuller-Rowell et al., 1996). Minor species transport is solved for $\mathrm{N}\left({ }^{4} \mathrm{~S}\right), \mathrm{N}\left({ }^{2} \mathrm{D}\right), \mathrm{NO}, \mathrm{HO}_{\mathrm{x}}=\mathrm{OH}+$ $\mathrm{HO}_{2}+\mathrm{H}, \mathrm{H}_{2} \mathrm{O}, \mathrm{H}_{2}, \mathrm{CO}, \mathrm{CO}_{2}, \mathrm{CH}_{4}, \mathrm{NO}_{2}, \mathrm{O}\left({ }^{1} \mathrm{D}\right)$, and He. $\mathrm{H}_{2} \mathrm{O}_{2}$ and $\mathrm{O}\left({ }^{1} \mathrm{D}\right)$ are assumed to be in a state of photochemical equilibrium.

(VI) High-latitude ionospheric parameters are determined from the Coupled Sheffield University High-Latitude Ionosphere Model (Quegan et al., 1982; Fuller-Rowell et al., 1996), which solves for electron and ion temperature; field-aligned velocities and distribution of $\mathrm{O}^{+}$ and $\mathrm{H}^{+}$; the distribution of $\mathrm{O}_{2}{ }^{+}, \mathrm{N}_{2}{ }^{+}, \mathrm{NO}^{+}, \mathrm{N}^{+}$assuming photochemical equilibrium; and electron density. High-latitude auroral precipitation, including the effect of medium energy electrons, is taken from the TIROS/NOAA auroral precipitation statistical model (Fuller-Rowell and Evans, 1987; Codrescu et al., 1997), and electric field strength from Foster et al. (1986). The effect of high-latitude, small-scale electric field variability is also included (after Codrescu et al., 2000).

(VII) A Hybrid Matsuno-Lindzen parameterisation, as outlined by Meyer (1999), is used to calculate gravity wave drag. The source spectrum at $20 \mathrm{~km}$ consists of 19 waves with velocities ranging between $\pm 60 \mathrm{~ms}^{-1}$, propagating in both the zonal and meridional directions. The distribution of wave amplitudes is Gaussian about $0 \mathrm{~ms}^{-1}$, with the zero velocity wave having an amplitude 20 times that of the $\pm 60 \mathrm{~ms}^{-1}$ waves. The spectrum is filtered between $20 \mathrm{~km}$ and the lower boundary at about $30 \mathrm{~km}$, in accordance with the output from the Horizontal Wave Model (Hedin et al., 1993). The overall intermittency factor and peak amplitude used in the parameterisation have been selected to attain a reasonable mesospheric wind structure and comparable wave drag profiles, as calculated by other models. The vertical eddy diffusion rate coefficient is either calculated
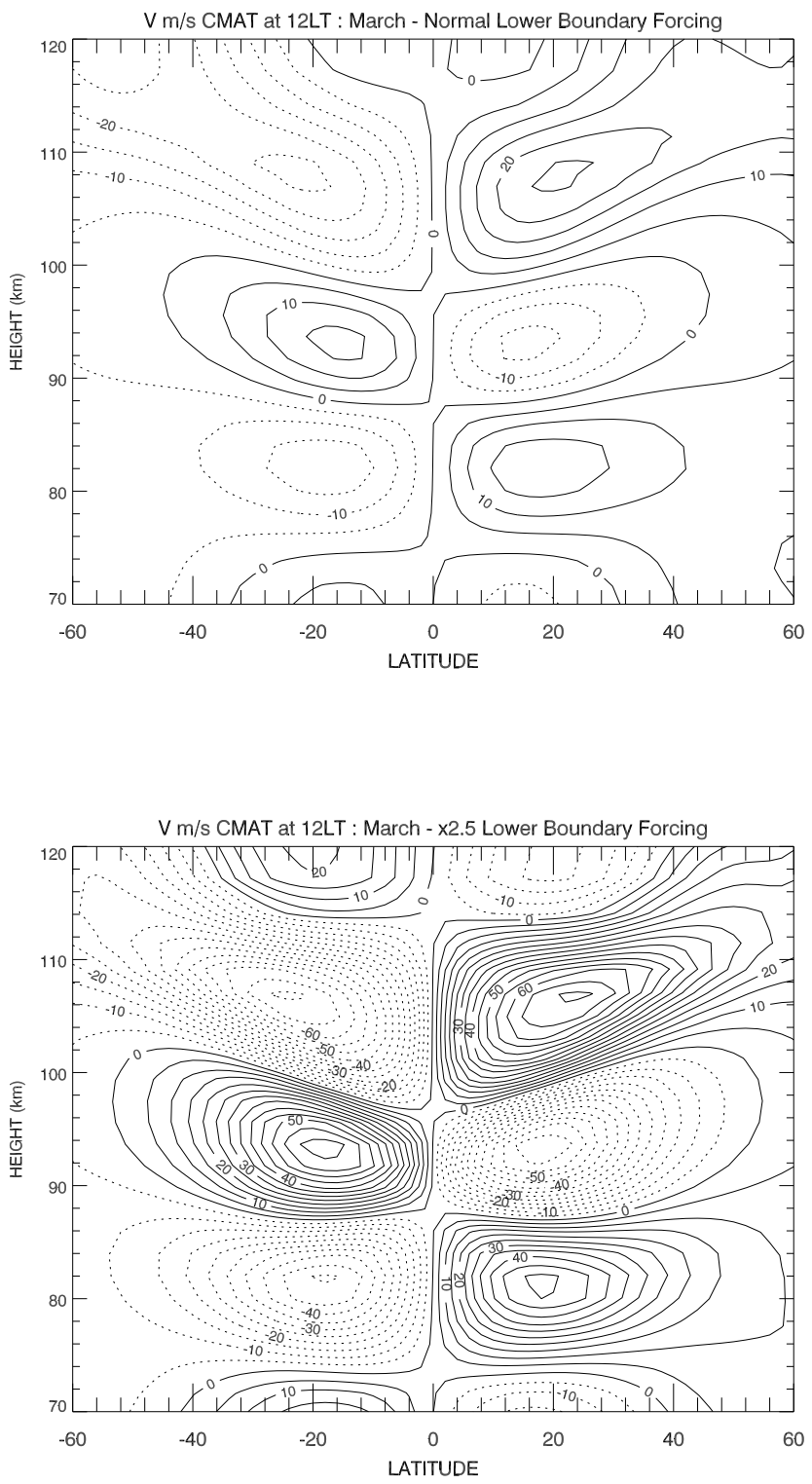

Fig. 3. Meridional winds $\left(\mathrm{ms}^{-1}\right)$ as calculated by CMAT for March at 12:00 LT, with normal lower boundary diurnal tidal forcing (top), and $\times 2.5$ lower boundary diurnal tidal forcing (bottom) southward wind contours are dotted.

in the gravity drag scheme or taken as a height dependent global mean based on the climatology calculated by Garcia and Solomon (1985), used in the Global Scale Wave Model (GSWM, Hagan et al., 1995)

(VIII) Lower boundary seasonal forcing is from MSIS-E90 (Hedin, 1991) and lower boundary tidal forcing from GSWM output (Hagan, private communication, 1999). 

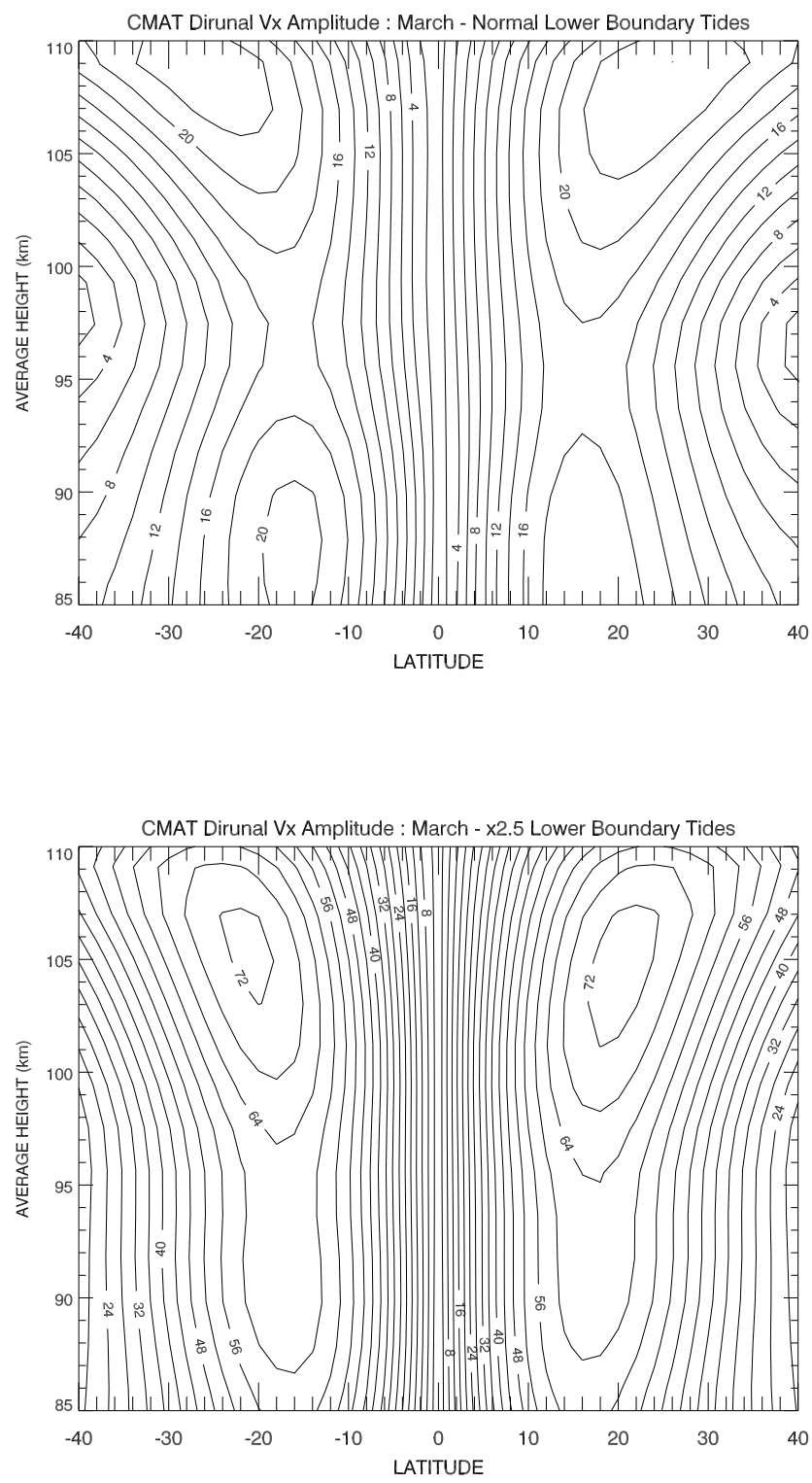

Fig. 4. Diurnal amplitude structure of meridional winds $\left(\mathrm{ms}^{-1}\right)$ as calculated by CMAT for March, with normal lower boundary tidal forcing (top), and $\times 2.5$ lower boundary tidal forcing (bottom).

\section{The CMAT model runs}

\subsection{The standard run}

The standard CMAT run presented here is for the March equinox at solar cycle minimum $(F 10.7=76)$, with low geomagnetic activity $\left(K_{p}=2+\right.$, auroral power input $=8 \mathrm{GW}$, cross polar cap electric potential $=36 \mathrm{kV})$. The eddy diffusion coefficient is taken as a height dependent global mean based on the climatology calculated by Garcia and Solomon (1985) used in the GSWM, with a peak of about $75 \mathrm{~m}^{2} / \mathrm{s}$ at about $100 \mathrm{~km}$. Lower boundary tidal forcing is taken from GSWM output, with a diurnal $(1,1)$ geopotential height amplitude of $14 \mathrm{~m}$ and a phase of $20.8 \mathrm{~h}$. The calculation of

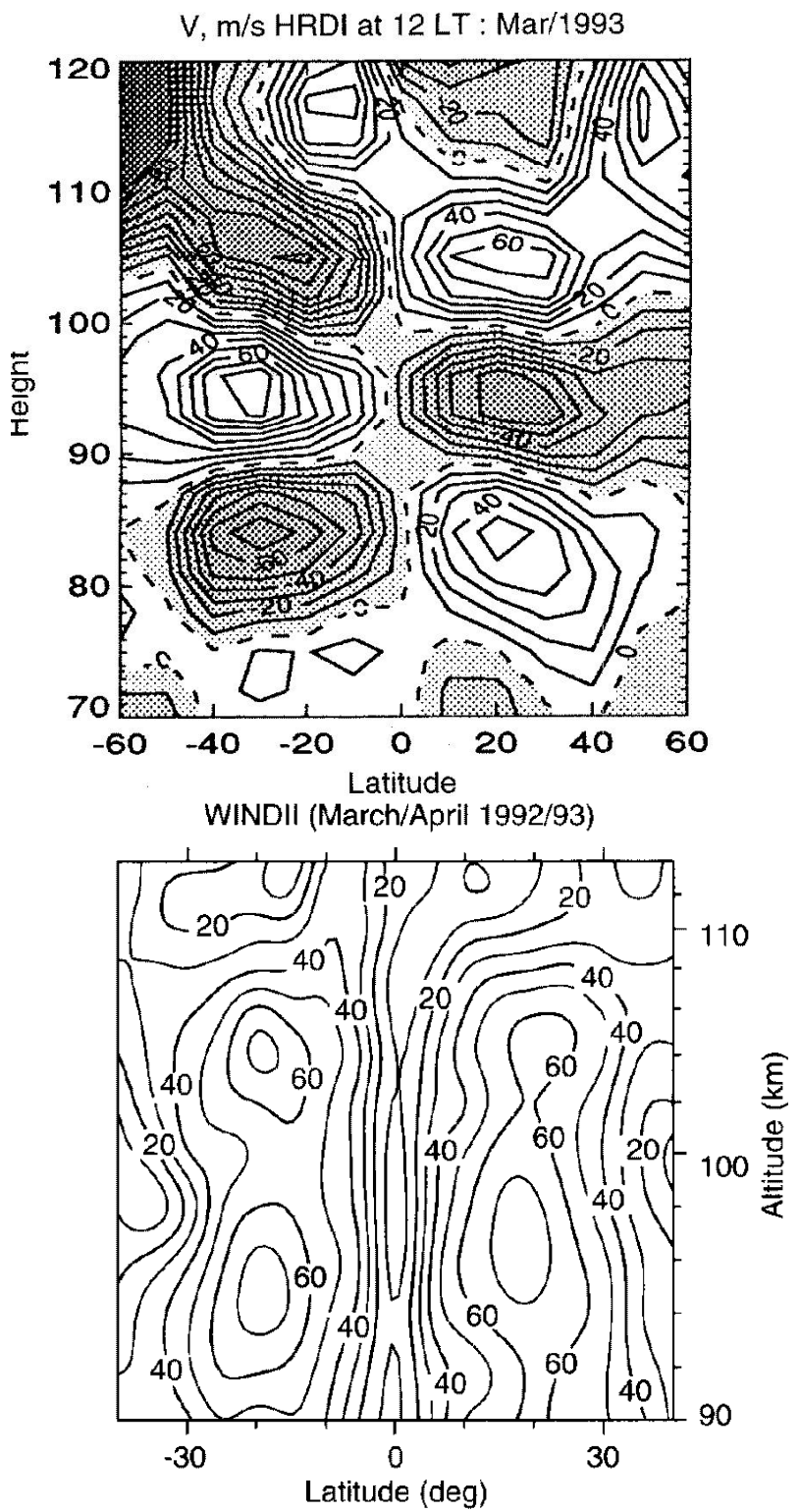

Fig. 5. Meridional winds $\left(\mathrm{ms}^{-1}\right)$ at 12:00 LT for March, as measured by HRDI (top) (from Yudin et al., 1997), with southward winds shaded, and the diurnal amplitude structure of meridional winds $\left(\mathrm{ms}^{-1}\right)$ as measured by WINDII (bottom) (from Akmaev et al., 1997).

the atomic oxygen $557.7 \mathrm{~nm}$ green line emission only considers the source due to recombination (Murtagh et al., 1990). CMAT was run for 30 days in a steady state.

\subsection{The increased lower boundary tidal forcing run}

CMAT is in reasonable agreement with regards to the morphology of the diurnal tide in the MLT region, although it underestimates the amplitudes by about a factor of 2-3. Wind Imaging Doppler Images (WINDII) measured maximum amplitudes of 60-70 $\mathrm{ms}^{-1}$ (McLandres et al., 1996), compared to about $20 \mathrm{~ms}^{-1}$ as calculated by CMAT. The reason for this 

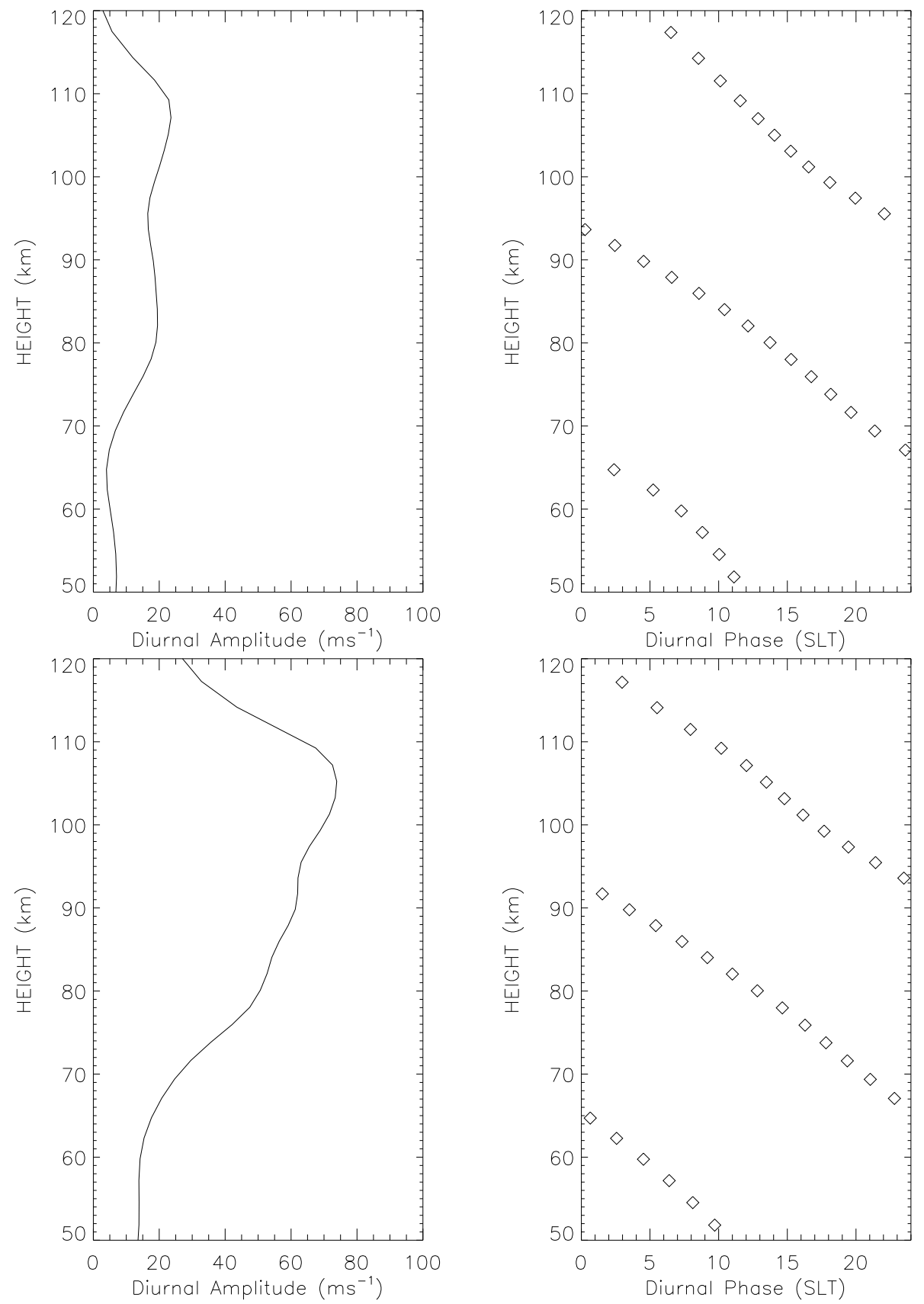

Fig. 6. Meridional winds $\left(\mathrm{ms}^{-1}\right.$ ) at 12:00 LT for March, as measured by HRDI (top) (from Yudin et al., 1997), with southward winds shaded, and the diurnal amplitude structure of meridional winds $\left(\mathrm{ms}^{-1}\right.$ ) as measured by WINDII (bottom) (from Akmaev et al., 1997).

shortfall is due to the representation of the gravity wave dissipation in the model. This has also been encountered in studies with the NCAR TIME-GCM (Roble and Ridley, 1995; Roble and Shepherd, 1997; Yee et al.,1997). As with the NCAR TIME-GCM, CMAT runs without gravity wave dissipation to produce diurnal tidal amplitudes in close agreement with the observations. In order to attain similar upper mesospheric amplitudes to those observed, Roble and Shepherd (1997) increased the lower boundary tidal forcing of the NCAR TIME-GCM by a factor of 2.5. This factor is also applied in this study to the second CMAT run, such that the peak geopotential height amplitude of the lower boundary $(1,1)$ diurnal tidal forcing is $35 \mathrm{~m}$. All other model inputs are unchanged with respect to the standard run.

\section{CMAT results and discussion}

\subsection{CMAT mean background atmospheric structure}

CMAT zonal mean temperature and zonal wind fields are shown in Fig. 1, and similar plots from the Mass Spectrome- 

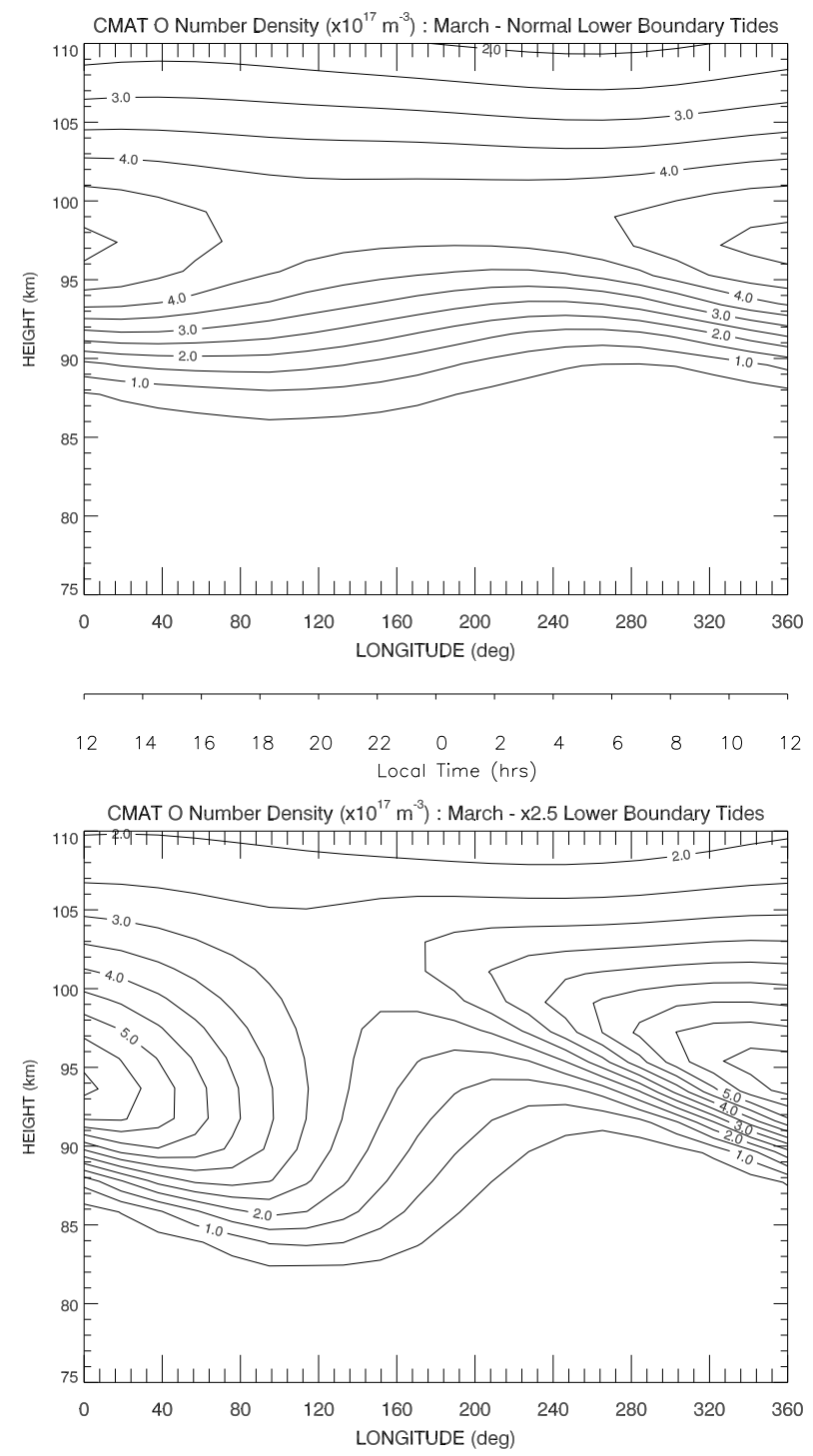

$\begin{array}{lllllllllllll}12 & 14 & 16 & 18 & 20 & 22 & 0 & 2 & 4 & 6 & 8 & 10 & 12\end{array}$

Fig. 7. Local time variation of atomic oxygen number density $\left(\times 10^{17} \mathrm{~m}^{-3}\right)$ as calculated by CMAT for 12:00 LT March at the equator, with normal lower boundary tidal forcing (top), and $\times 2.5$ lower boundary tidal forcing (bottom).

ter and ground-based Incoherent Scatter (MSIS-E90) empirical model (Hedin, 1991), and the empirical Horizontal Wind Model (HWM) (Hedin et al., 1993), are shown in Fig. 2. The CMAT middle atmosphere temperature structure is in reasonable agreement with the MSIS-E90 for similar geophysical conditions. Both plots show a maximum stratopause temperature of about $280 \mathrm{~K}$ in the $45-50 \mathrm{~km}$ height region. The mesopause structure does, however, differ slightly in that CMAT has a local temperature maximum at about $90 \mathrm{~km}$, associated with exothermic chemical heating. This global feature has been simulated in other modelling studies (Roble, 1995; Berger and von Zahn, 1999). Both CMAT and MSISE90 give mesopause minima of about $180 \mathrm{~K}$ at high-latitudes

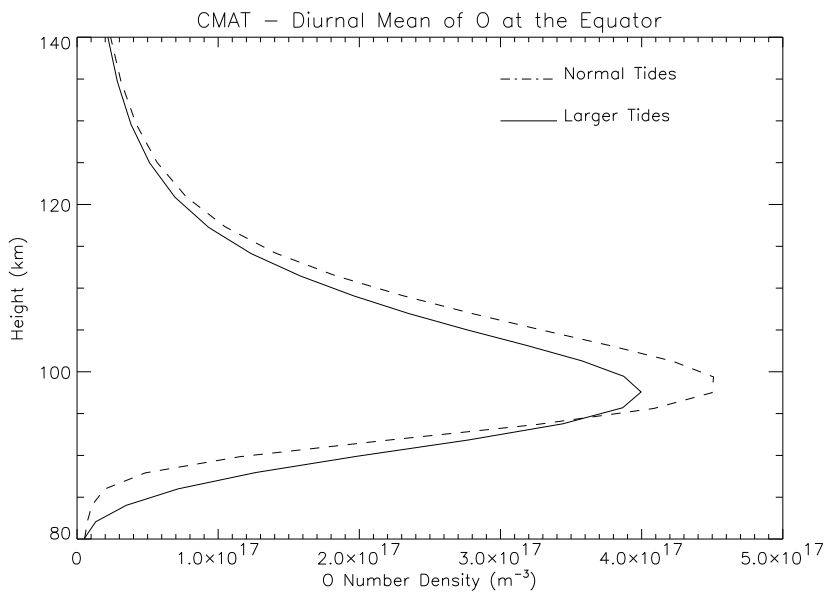

Fig. 8. Diurnal mean of atomic oxygen at the equator as calculated by CMAT with normal (dashed) and $\times 2.5$ lower boundary tidal forcing (solid).

in the $100 \mathrm{~km}$ region.

The general morphology of the CMAT zonal mean zonal wind field is in agreement with HWM, though significant differences are present. The mid-latitude eastward zonal jets in the $55-60 \mathrm{~km}$ region, as calculated by CMAT, have a maximum of about $38 \mathrm{~ms}^{-1}$, compared to $28 \mathrm{~ms}^{-1}$ given by HWM. Furthermore, CMAT is unable to reproduce the equatorial and subtropical eastward winds in the $45-70 \mathrm{~km}$ height region. The equatorial westward wind structure between 70$100 \mathrm{~km}$ is more extended in altitude in CMAT than in HWM, which shows a reversal at about $110 \mathrm{~km}$. The discrepancies between CMAT and observed wind and temperature fields are most likely due to the representation of gravity wave dissipation in CMAT, as discussed in the previous section.

\subsection{The effect of the diurnal tide}

Figure 3 shows the meridional wind structure at 12:00 LT, as calculated by CMAT, for normal (top) and increased (bottom) lower boundary tidal forcing. With increased forcing, CMAT is in close agreement with meridional winds measured by the High Resolution Doppler Imager (HRDI) on board the UARS satellite (compare Fig. 3 (bottom) to Fig. 5 (top), Yudin et al., 1997). Figure 4 gives the diurnal amplitude structure of the meridional wind, as calculated by CMAT, for the two runs. Without increased lower boundary tidal forcing, CMAT gives peak amplitudes of about $20 \mathrm{~ms}^{-1}$, compared to $75 \mathrm{~ms}^{-1}$ with increased forcing. The amplitude structure determined from WINDII observations is given in Fig. 5 (bottom). The increased tidal forcing run is in reasonable agreement with the HRDI data between 80$100 \mathrm{~km}$, but it overestimates the amplitude between 100$110 \mathrm{~km}$. The diurnal amplitude and phase at $20 \mathrm{~N}$ with normal and increased lower boundary tidal forcing are shown in Fig. 6. The phase variation with height is in reasonable agreement with WINDII measurements (e.g. Hagan et al., 1997). CMAT gives a phase of about $22 \mathrm{~h}$ at $96 \mathrm{~km}$ during 

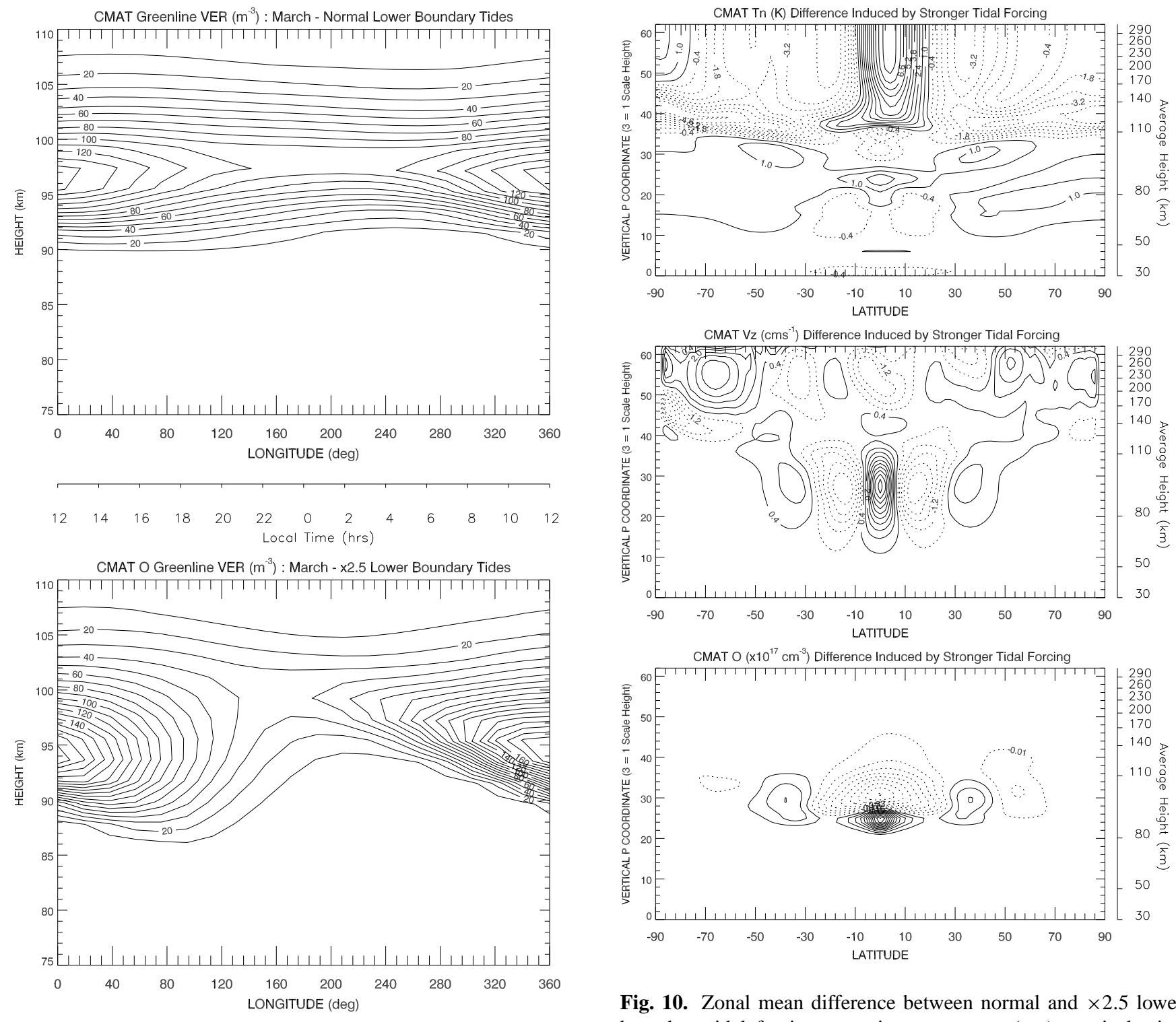

Fig. 10. Zonal mean difference between normal and $\times 2.5$ lower boundary tidal forcing runs, in temperature (top), vertical wind (middle, positive values denote increase in upward winds), and atomic oxygen (bottom).

Fig. 9. Local time variation of $557.7 \mathrm{~nm}$ green line volume emission rate $\left(\mathrm{s}^{-1} \mathrm{~m}^{-3}\right)$ as calculated by CMAT for March at the equator, with normal lower boundary tidal forcing (top), and $\times 2.5$ lower boundary tidal forcing (bottom).

equinox, compared to $23 \mathrm{~h}$ as measured by WINDII. There is little change in the CMAT simulated diurnal phase structure with increased lower boundary tidal forcing. Figure 9 shows $\mathrm{O} 557.7 \mathrm{~nm}$ green line volume emission rates, as calculated by CMAT, for both runs. With increased tidal forcing, the longitudinal morphology of the green line emission is in reasonable agreement with WINDII observations (Shepherd et al., 1995). The absolute magnitudes are, however, smaller in CMAT than those observed by about a factor of 2 , suggesting that the overall $\mathrm{O}$ number densities are too low. An increase in overall $\mathrm{O}$ of about $25 \%$ would re-

move this discrepancy. As suggested by Roble and Shepherd (1997), lower peak O densities may be in some part due to an overestimation of eddy diffusion in the model. Figure 7 shows the local time variation of atomic oxygen at the equator, as calculated by CMAT, for the two runs. In agreement with the NCAR TIME-GCM simulations presented by Roble and Shepherd (1997), the atomic oxygen layer between 90$100 \mathrm{~km}$ is strongly affected by tides at the equator. Oscillations penetrate the peak layer, resulting in much stronger diurnal variation due to changes in the overall density and vertical transport. The change in the diurnal cycle local maximum of $\mathrm{O}$ density does, however, differ between CMAT and the NCAR TIME-GCM. By increasing the lower boundary tidal forcing in the NCAR TIME-GCM, Roble and Shepherd (1997) found that the local maximum of O number density at the equator, which occurs around 12:00 LT, decreased from 


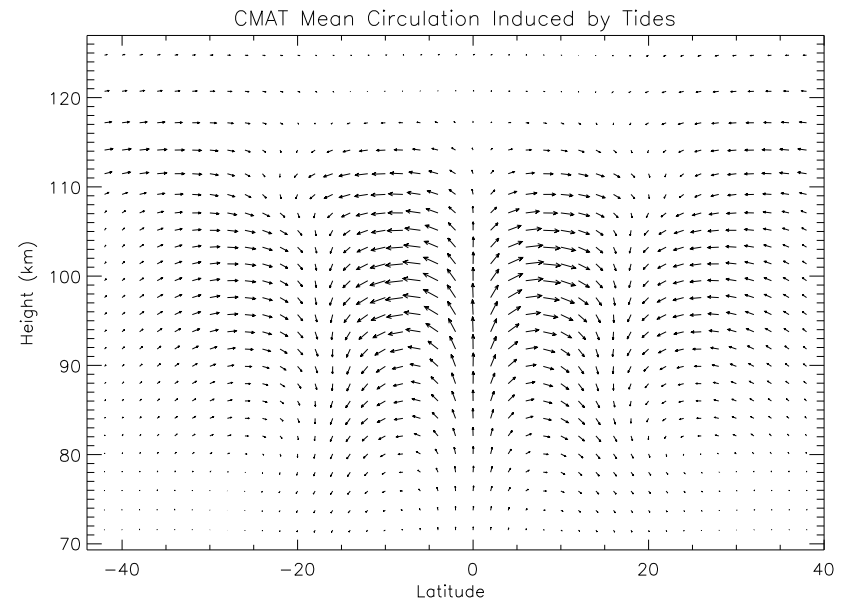

Fig. 11. Mean circulation induced with increased lower boundary tidal forcing as calculated by CMAT. The vertical winds have been scaled up by a factor of 80 . Maximum vertical winds at the equator in the $90-100 \mathrm{~km}$ height region are about $3 \mathrm{~cm}^{-\mathrm{s}}$, and the maximum meridional winds in the same height region at $\pm 10^{\circ}$ are about $7.5 \mathrm{~ms}^{-1}$.

about $6 \times 10^{17}$ to $5 \times 10^{17} \mathrm{~m}^{-3}$. In CMAT, the opposite occurs, with an increase of $5 \times 10^{17}$ to $6 \times 10^{17} \mathrm{~m}^{-3}$. Since the main mechanisms responsible for the diurnal variation of $\mathrm{O}$ are increased with stronger tides, it follows that this can result in larger extremes of the $\mathrm{O}$ number density variation. This would not be the case if the overall depletion of mean $\mathrm{O}$ was sufficiently large, for example, due to the net increase in the recombination, as discussed previously. It should be noted, however, that although Akmaev and Shved (1980) reported a decrease in $\mathrm{O}$ above $100 \mathrm{~km}$ due to tidal induced recombination; they showed a slight increase in peak $\mathrm{O}$ densities at about $95 \mathrm{~km}$. This may be in some part due to the omission of mean background circulation associated with tidal dissipation in their 1-dimensional model. The peak $\mathrm{O}$ density in the TIME-GCM occurs at about $100 \mathrm{~km}$ for weak tidal forcing, which is about $3 \mathrm{~km}$ higher than in CMAT. This may account for the decrease rather than the increase in mean $\mathrm{O}$, simulated in CMAT with increased tidal forcing. Figure 8 shows the diurnal mean atomic oxygen vertical profile at the equator for both CMAT runs. The mean peak in $\mathrm{O}$ is seen to decrease by about $11 \%$, and the integrated column between $80-140 \mathrm{~km}$ by about $4 \%$. Between about $80-90 \mathrm{~km}$, stronger tidal forcing increases $\mathrm{O}$ number densities, as expected with tidal oscillations of the $O$ peak layer that penetrate to lower altitudes.

Figure 10 shows the difference fields for zonal mean temperature (top), zonal mean vertical wind (middle), and zonal mean atomic oxygen (bottom), caused by stronger lower boundary tidal forcing. The trends in atomic oxygen and temperature between $\pm 20^{\circ}$ in latitude are in agreement with the modelling study of Forbes and Roble (1993), and the cell-like vertical wind structure induced by increased dissipating tides is similar to mean vertical wind fields derived from WINDII observations (Fauliot et al., 1997). Figure 11 illustrates the circulation pattern induced by tidal dissipation. The production/loss terms for $\mathrm{O}_{\mathrm{x}}$ calculated by CMAT show that mean circulation induced by tidal dissipation contributes to the change in mean $\mathrm{O}$ in the equatorial region. The magnitude of this effect, compared to the increased recombination mechanism is, however, very difficult to determine from CMAT output. This is due to the complexity associated with a self-consistent model, and the fact that the numerical scheme is in fixed pressure coordinates. The calculation of net chemical loss in a tidally displaced air parcel due to recombination effects would best be suited to a Lagrangian analysis, tracking the air parcel as it is vertically advected through the diurnal cycle. Therefore, the following analysis of production and loss is only able to highlight the relative contributions of the terms in the $\mathrm{O}_{\mathrm{x}}$ production/loss equation, and can give little information as to the components in each term. For example, the net loss associated with vertical advection may have two components. It could be due to a combination of net upward vertical motion of $\mathrm{O}$ poor air, and the increased recombination effect associated with tidal oscillations.

Figure 12 (top) shows the $\mathrm{O}_{\mathrm{x}}$ mass mixing ratio at $98 \mathrm{~km}$ $16^{\circ} \mathrm{N}$ for a CMAT run when increased lower boundary forcing is introduced. It takes 2-3 days for the effect of increased tides to fully propagate to this altitude, after which the amplitude in the oscillations of $\mathrm{O}_{\mathrm{x}}$ is seen to increase. A decrease in the mass mixing ratio is observed, as seen in the diurnal mean $\mathrm{O}_{\mathrm{x}}$ number density trend. Figure 12 (bottom) shows the diurnal mean production and loss terms of $\mathrm{O}_{\mathrm{x}}$ mass mixing ratio for the same location and run. As the tides become stronger at this altitude, diurnal loss due to horizontal advection increases. The contribution from diurnal mean vertical advection is positive due to net downward motion, though it seems to lag behind the loss due to horizontal advection. This would be consistent with increased chemical loss in vertically displaced parcels of air as the increased tides first propagate into this region. As the concentration of $\mathrm{O}$ falls, this effect would decrease, and the positive contribution of vertical advection would catch up with the negative horizontal terms. The chemical and meridional advection productionloss terms slowly increase, acting to slow the rate of loss of $\mathrm{O}_{\mathrm{x}}$. With respect to chemistry, this is consistent with the lower $\mathrm{O}_{\mathrm{x}}$ concentrations, leading to decreased recombination. This results in an overall increase in chemical production, since the solar dissociation production of $\mathrm{O}$ is largely unaffected by increased tides. The slow increase in meridional advection is consistent with falling concentrations at the equator. This acts to reduce the latitudinal gradient $\mathrm{O}_{\mathrm{x}}$, which, in turn, decreases the magnitude of the loss due to net outward flow from the equator.

The change in the mean temperature with increased tidal forcing was shown in Fig. 10 (top). Although the changes are small, it is interesting to note the processes responsible, since they highlight the complexity of the coupling mechanisms in the MLT region. Analysis of the production and loss terms in the CMAT energy equation show that the decrease in temperature between $90-110 \mathrm{~km}$ and the increase below $90 \mathrm{~km}$ are 

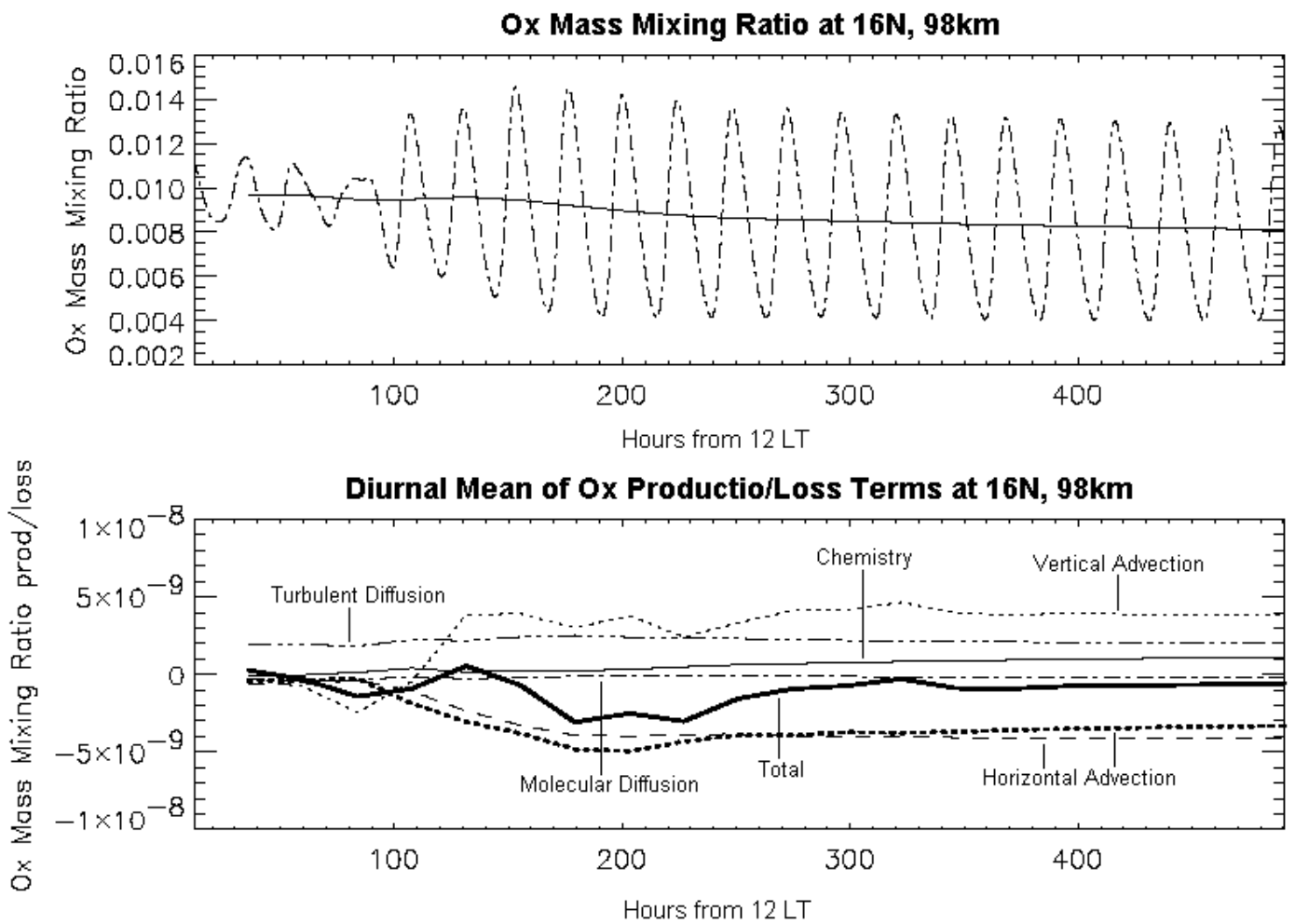

Fig. 12. (top): $\mathrm{O}_{\mathrm{x}}$ mass mixing ratio at $16^{\circ} \mathrm{N}, 98 \mathrm{~km}$, (dotted line), and diurnal mean of $\mathrm{O}_{\mathrm{x}}$ mass mixing ratio (solid line) as calculated by CMAT when introducing tides; (bottom) Diurnally averaged production and loss terms of $\mathrm{O}_{\mathrm{x}}$ at the equator for the same run and location.

in some part due to changes in exothermic chemical heating. This process is the major energy source in the MLT region, as calculated by CMAT (see Fig. 13). The global mean values shown are in reasonable agreement with previous studies (Mlynczak and Solomon, 1993; Reis et al., 1994; Ward and Fomichev, 1993; Zhu et al., 1999). Increased tides deplete O in the $90-110 \mathrm{~km}$ region, and increase it below $90 \mathrm{~km}$. This leads to a decrease in chemical heating between $90-100 \mathrm{~km}$ and an increase below $90 \mathrm{~km}$, with corresponding changes in temperature. Similar runs with chemical heating deactivated above $75 \mathrm{~km}$ show similar temperature variations due to increased tides, but with a smaller magnitude. The remaining variations with chemical heating deactivated are due to changes in advection. Similar to the changes in mean O, below $90 \mathrm{~km}$, the increase in temperature is due to an increase in the positive contribution of the vertical advection term, whereas between $90-110 \mathrm{~km}$, there is an increased cooling due to horizontal advection.

\section{Conclusions}

Similar runs to those carried out by Roble and Shepherd (1997) have been made with a new mesosphere and thermosphere general circulation model. CMAT was able to simulate many diurnal tidal features observed in the MLT region. The runs suggest that tides act to reduce the peak in mean $\mathrm{O}$ density at the equator, but not sufficiently so that the diur-

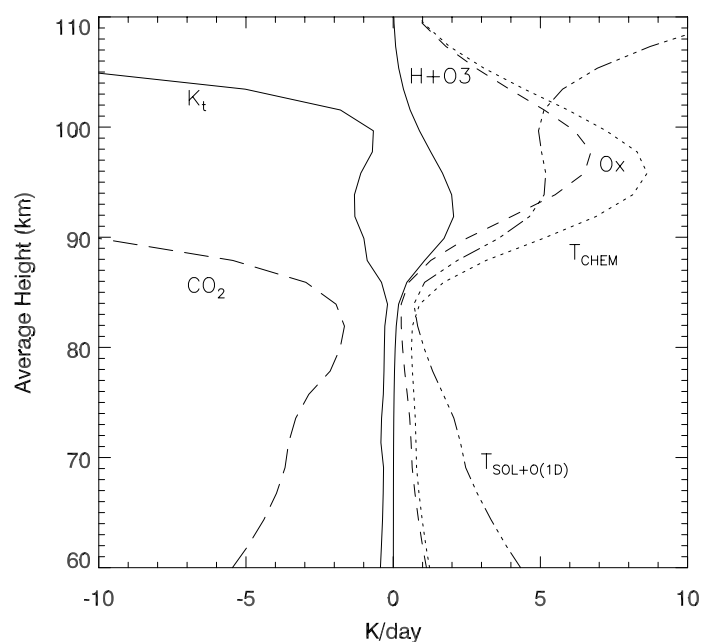

Fig. 13. The main CMAT global mean heating and cooling rates in the MLT region in $\mathrm{Kday}^{-1}$ with normal lower boundary tidal forcing. $\mathrm{T}_{\mathrm{SOL}+\mathrm{O}(1 \mathrm{D})}$ is the total of heating due to the absorption of solar radiation and the quenching of $\mathrm{O}\left({ }^{1} \mathrm{D}\right)$; $\mathrm{T}_{\text {chem }}$ is total exothermic chemical heating; $\mathrm{H}+\mathrm{O}_{3}$ is heating due to the reaction of hydrogen and ozone (with a heating efficiency of 0.6); $\mathrm{O}_{\mathrm{x}}$ is heating due to oxygen recombination reactions; $\mathrm{CO}_{2}$ is cooling due to $15 \mu \mathrm{m}$ emission from $\mathrm{CO}_{2} ; \mathrm{K}_{\mathrm{t}}$ is cooling due to turbulent heat conduction.

nal cycle local maximum decreases with increased tidal forcing. The diurnal cycle local maximum values of green line 
emission at the equator increased with stronger lower boundary tidal forcing. Changes in mean circulation induced by tidal dissipation would appear to have a strong influence on mean $\mathrm{O}$. Analysis of the diurnal mean production-loss terms in the $\mathrm{O}_{\mathrm{x}}$ continuity equation at $16 \mathrm{~N}, 98 \mathrm{~km}$ show that the horizontal advection components are of similar magnitude to the vertical component. Changes in mean temperature were influenced by both changes in exothermic chemical heating associated with changes in the $\mathrm{O}$ distribution and mean circulation.

CMAT is still in a relatively formative stage, and will be subject to future improvements. As discussed previously, the shortfall in diurnal tidal amplitude, and the discrepancies between modelled and observed zonal mean wind and temperature, are most likely due to the representation of gravity wave drag in the model. This will be addressed with the update to a more sophisticated parameterisation, such as that of Hines (1997a, b).

Acknowledgement. The authors wish to thank I. C. F. MuellerWodarg for his helpful discussion, and the two referees for their helpful comments. The research is supported by grants from PPARC. The work was carried out on the Miracle supercomputer, at the UCL Hyperspace computing centre, which is funded by U. K. Particle Physics and Astronomy Research Council.

The Editor in Chief thanks R. A. Akmaev and another referee for their help in evaluating this paper.

\section{References}

Akmaev, R. A. and Shved, G. M.: Modelling of the composition of the lower thermosphere taking account of the dynamics with application to tidal variations of the [OI] 5577 Åairglow, J. Atmos. Terr. Phys., 42, 705-716, 1980.

Akmaev, R. A., Yudin, V. A., and Ortland, D. A.: SMLTM simulations of the diurnal tide: comparison with UARS observations, Ann. Geophysicae, 15, 1187-1197, 1997.

Akmaev, R. A.: Simulation of tides with a spectral mesosphere/thermosphere model, Geophys. Res. Lett., 23, 2173, 1996.

Allen M., Lunine, J. I., and Lang, Y. L.: The vertical distribution of ozone in the mesosphere and lower thermosphere, J. Geophys. Res., 89, 4841, 1984.

Angelats i Col, M. and Forbes, J. M.: Dynamical influences on atomic oxygen and 5577 Åmission rates in the lower thermosphere, Geophys. Res. Letts., 25, 4, 461-464, 1998.

Bates, D. R.: The temperature of the upper atmosphere, Proc. Phys. Soc., London, 64B, 805, 1951.

Berger, U. and von Zahn, U.: The two-level structure of the mesopause: A model study, J. Geophys. Res., 104, $22083-$ 22 093, 1999.

Burrage, M. D., Hagan, M. E., Skinner, W. R., Wu, D. L., and Hays, P. B.: Long-term variability in the solar diurnal tide observed by HRDI and simulated by the GSWM, Geophys. Res. Lett., 22, 2641, 1995.

Codrescu, M. V., Fuller-Rowell, T. J., Roble, R. G., and Evans, D. S.: Medium energy particle precipitation influences on the mesosphere and lower thermosphere, J. Geophys. Res., 102, A9, 19997, 1997.
Codrescu, M. V., Fuller-Rowell, T. J., Foster, J. C., Holt, J. M. and Cariglia. S. J.: Electric field variability associated with the Millstone Hill electric field model, J. Geophys. Res., 105, A3, 5265, 2000.

DeMore, W. B., Sander, S. P., Howard, C. J., Ravishankara, A. R., Golden, D. M., Kolb, C. E., Hampson, R. F., Kurylo, M. J., and Molina, M. J.: Chemical kinetics and photochemical data for use in stratospheric modeling, NASA Jet Propulsion Laboratory, JPL Publication, 97-94, 1997.

Fauliot, V., Thuillier, G., and Vial, F.: Mean vertical wind in the mesosphere-lower thermosphere region $(80-120 \mathrm{~km})$ deduced from the WINDII observations on board UARS, Ann. Geophysicae, 15, 1221-1231, 1997.

Fomichev, V. I. and Blanchet, J.-P.: Development of the new $\mathrm{CCC} / \mathrm{GCM}$ radiation model for extension into the middle atmosphere, Atmos. Ocean, 33, 513, 1995.

Fomichev, V. I., Blanchet, J.P., and Turner, D. S.: Matrix parameterization of the $15 \mu \mathrm{m}$ band cooling in the middle and upper atmosphere for variable $\mathrm{CO}_{2}$ concentration, J. Geophys. Res., 103, D10, 11 505-11 528, 1998.

Forbes, J. M. and Roble, R. G.: Acceleration, heating, and compositional mixing of the thermosphere due to upward propogating tides, J. Geophys. Res., 98, A1, 311-321, 1993.

Foster, J. C., Holt, J. M., Musgrove, R. G., and Evans, D. S.: Ionospheric convection associated with discrete levels of particle precipitation, Geophys. Res. Lett., 13, 656, 1986.

Fuller-Rowell, T. J. and Rees, D.: A three-dimensional timedependant global model of the thermosphere, J. Atmos. Sci, 37, 2545, 1980.

Fuller-Rowell, T. J. and Evans, D. S.: Height-integrated Pedersen and Hall conductivity patterns inferred from the TIROS-NOAA satellite data, J. Geophys. Res., 92, 7606, 1987.

Fuller-Rowell, T. J.: Modelling the solar cycle change in nitric oxide in the thermosphere and upper mesosphere, J. Geophys. Res., 98, 1571, 1992.

Fuller-Rowell, T. J., Rees, D., Quegan, S., Moffett, R. J., Codrescu, M. V., and Millward, G. H.: A coupled thermosphere ionosphere model, Solar terrestrial energy program (STEP), handbook of ionospheric models, (Ed) Schunk, R. W., 1996.

Garcia, R. R. and Solomon, S.: A numerical model of the zonally averaged dynamical and chemical structure of the middle atmosphere, J. Geophys. Res., 90, 3850-3868, 1985.

Hagan, M. E., Forbes, J. M., and Vial, F.: On modelling migrating solar tides, Geophys.Res.Lett., 22, 893-896, 1995.

Hagan, M. E., McLandres, C., and Forbes, J. M.: Diurnal tidal variability in the upper mesosphere and lower thermosphere, Ann. Geophysicae, 15, 1176-1186, 1997.

Harris, M. J.: A new coupled terrestrial mesosphere-thermosphere general circulation model: Studies of dynamic, energetic, and photochemical coupling in the middle and upper atmosphere, PhD Thesis, University of London, UK, submitted, 2000.

Hedin, A. E.: Extension of the MSIS Thermosphere model into the middle and lower atmosphere, J. Geophys. Res., 96, A2, 1159, 1991.

Hedin, A. E., Flemming, E. L., Manson, A. H., Schmidlin, F. J., Avery, S. K., and Franke, S. J.: Empirical wind model for the middle and lower atmosphere 1: Local time average, NASA Tech. Memo. NASA TM-104 581, 1993.

Hines, C. O.: Doppler Spread parameterisation of gravity wave momentum deposition in the middle atmosphere, Part I, Basic formulation, J. Atmos. Solar-Terr. Phys., 59, 371-386, 1997a.

Hines, C. O.: Doppler Spread parameterisation of gravity wave mo- 
mentum deposition in the middle atmosphere, Part II, Broad and quasi monochromatic spectra, and implementation, J. Atmos. Solar-Terr. Phys., 59, 387-400, 1997 b.

Kockarts, G.: Nitric oxide cooling in the terrestrial thermosphere, Geophys. Res. Lett., 7, 2, 137, 1980.

McLandres, C., Shepherd G. G., and Solheim B. H.: Satellite observations of thermospheric tides : Results from the wind imaging interferometer on UARS, J. Geophys. Res., 101, 4093-4114, 1996.

McLandres, C.: Seasonal variability of the diurnal tide: Results from the Canadian middle atmosphere general circulation model, J. Geophys. Res., 102, D9, 29747, 1997.

Meyer, C.: Gravity wave interactions with mesospheric planetary waves: A mechanism for penetration into the thermosphereionosphere system, J. Geophys. Res., 104, 28 181-28 196, 1999.

Millward, G., Moffett, R. J., Quegan, S., and Fuller-Rowell, T. J.: A Coupled Thermosphere-Ionosphere-Plasmasphere Model (CTIP), Solar Terrestrial Energy Program (STEP) Handbook, (Ed) Schunk, R. W., 1996.

Miyahara, S., Portnyagin, Yu. I., Forbes, J. M., and Solovjeva, T. V.: Mean zonal acceleration and heating of the $70-110 \mathrm{~km}$ region, J. Geophys. Res., 96, 1225-1238, 1991.

Mlynczak, M. G. and Solomon, S.: Middle atmosphere heating by exothermic chemical reactions involving odd hydrogen species, Geophys. Res. Lett., 18, 37-40, 1991.

Mlynczak, M. G. and Solomon, S.: A detailed study of heating efficiency in the middle atmosphere, J. Geophys. Res., 98, $10517-$ $10541,1993$.

Murtagh, D. P., Witt, G., Stegman, J., McCade, I. C., Llewellyn, E. J., Harris, F., and Greer, R. G. H.: An assessment of proposed $\mathrm{O}\left({ }^{1} \mathrm{~S}\right)$ and $\mathrm{O}_{2}\left(b^{1} \Sigma_{b}^{+}\right)$nightglow excitation parameters, Planet. Space. Sci., 38, 43, 1990.

Quegan, S., Bailey, G. J., Moffett, R. J., Heelis, R. A., FullerRowell, T. J., Rees, D., and Spiro, A. W.: A theoretical study of the distribution of ionisation in the high-latitude ionosphere and the plasmasphere: First results of the mid-latitude trough and the light ion trough, J. Atm. Terr. Phys., 44, 619, 1982.

Reis, M., Offerman, D., and Brasseur, G.: Energy released by recombination of atomic oxygen and related species at mesopause heights, J. Geophys. Res., 99, D7, 14 585, 1994.

Roble, R. G., Ridley E. C., and Dickenson, R. E.: On the global mean structure of the thermosphere, J. Geophys. Res., 92, A8, 8745-8758, 1987.

Roble, R. G. and Ridley, E. C.: A thermospheric-ionospheremesosphere-electrodynamics general circulation model (timeGCM): Equinox solar cycle minimum simulations (30-500 km), Geophys. Res. Letts., 21, 6, 417, 1994.
Roble, R.: Energetics of the mesosphere and thermosphere, Upper mesosphere and lower thermosphere: A review of experiment and theory, Geophysical monograph 87, AGU, 1995.

Roble, R. G. and Shepherd, G. G.: An analysis of wind imaging interferometer observations of $\mathrm{O}\left({ }^{1} \mathrm{~S}\right)$ equatorial emission rates using the thermosphere-ionosphere-mesosphere electrodynamics general circulation model, J. Geophys. Res., 102, A2, 2467, 1997.

Shepherd, G. G., McLandres, C., and Solheim, B. H.: Tidal influence on $\mathrm{O}\left({ }^{1} \mathrm{~S}\right)$ airglow emission rate distributions at the geographic equator as observed by WINDII, Geophys. Res. Lett., 22, 275, 1995

Solomon, S., Garcia, R. R., Olivero, J. J., Bevilacqua, R. M., Schartz, P. R., Clancy, R. T., and Muhleman, D. O.: Photochemistry and transport of carbon monoxide in the middle atmosphere, J. Atmos. Sci., 42, 1072, 1985.

Strobel, D. F.: Parameterization of the atmospheric heating rate from 15 to $120 \mathrm{~km}$ due to $\mathrm{O}_{2}$ and $\mathrm{O}_{3}$ absorption of solar radiation, J. Geophys. Res., 83, 6225, 1978.

Torr, M. R., Richards, P. G., and Torr, D. G.: A new determination of ultraviolet heating efficiency in the thermosphere, J. Geophys. Res., 85, 6819, 1980a.

Torr, M. R., Richards, P. G., and Torr, D. G.: The solar ultraviolet heating efficiency in the mid-latitude thermosphere, Geophys. Res. Lett., 6, 673, 1980b.

Ward, W. E. and Fomichev, V. I.: On the role of atomic oxygen on the dynamics and energy budget of the mesosphere and lower thermosphere, Geophys. Res. Lett, 12, 1199, 1993.

Wu, D. L., Hays, P. B., and Roble, R. G.: Doppler imager wind measurements with simulations from the NCAR thermosphereionosphere-mesosphere-electrodynamics circulation model, 101, D14, 19 147, 1997.

Yee, J.-H., Crowley, G., Roble, R. G., Skinner, W. R., Burrage, M. D., and Hays, P. B.: Global simulations and observations of $\mathrm{O}\left({ }^{1} \mathrm{~S}\right), \mathrm{O}_{2}\left({ }^{1} \Sigma\right)$ and $\mathrm{OH}$ mesospheric nightglow emissions, 102 , A9, 19949, 1997.

Yudin, V. A., Khattatov, B. V., Geller, M. A., Ortland, D. A., McLandres, C., and Shepherd, G. G.: Thermal tides and studies to tune the mechanistic tidal model using UARS observations, Ann. Geophysicae, 15, 1205-1220, 1997.

Yudin, V. A., Geller, M. A., Khattatov, B. V., Ortland, D. A., Burrage, M. D., McLandres, C., and Shepherd, G. G.: TMTM simulations of tides: Comparison with UARS observations, Geophys. Res. Lett., 25, 2, 221, 1998.

Zhu, X.: Numerical modeling of Chemical-Dynamical Coupling in the Upper Stratosphere and Mesosphere, J. Geophys. Res., 104, D19, 23 995, 1999. 